\title{
Vildagliptin promotes improvement in pulmonary arterial hypertension: incretin-based therapy at a follow-up of 3
}

\section{years}

Flavio Fontes Pirozzi ${ }^{1}$, Guilherme Lima Favaro ${ }^{2}$, Danielli Teixeira Lima Favaro ${ }^{1}$, Cleber Rinaldo Favaro ${ }^{1}$, Mikaell Alexandre Gouvea Faria $^{1,3}$, Luiz Gustavo de Quadros ${ }^{3}$ and Roberto Luiz Kaiser Júnior ${ }^{1,3}$

${ }^{1}$ Endocrinologist, UNILAGO Medical School, Sao Jose do Rio Preto, Brazil

${ }^{2}$ Medical Student, UNILAGO Medical School, Sao Jose do Rio Preto, Brazil

${ }^{3}$ Kaiser Clinic, Sao Jose do Rio Preto, Brazil

\begin{abstract}
Arterial pulmonary hypertension (PAH) is a rare complication in patients with metabolic syndrome. A good glycemic control is related to a better prognosis in diabetic patients with PAH. The presence of GLP-1 receptors in the lungs and the fact that this incretin promotes vasorelaxation in the pulmonary artery, place the incretin-based therapy as a possible treatment in patients with PAH. This case report will show the effect of vildagliptin - a DPP4 inhibitor - on the improvement of pulmonary symptoms and hemodynamic patterns in a patient with type 2 diabetes mellitus and $\mathrm{PAH}$.
\end{abstract}

\section{Introduction}

Pulmonary arterial hypertension $(\mathrm{PAH})$ is a serious condition that causes pulmonary vascular resistance, right heart failure, and death [1]. In its current classification, the most common form of PAH is idiopathic [2]. A study shows that more than a third of patients with idiopathic PAH present criteria for metabolic syndrome (MS) [3].

MS is the association of two or more metabolic problems such as obesity, dyslipidemia, diabetes and hypertension [4]. Among the components of MS, obesity, dyslipidemia and diabetes stand out as important causes of pulmonary diseases, including PAH [5].

One of the pathophysiological changes related to type 2 diabetes (T2D) is the decrease in the incretin effect with a marked reduction in the serum levels of glucagon-like-peptide 1 (GLP-1) and, consequently, a decrease in insulin secretion. GLP1 is secreted by L cells into the distal intestine after carbohydrate intake and is cleaved rapidly by the enzyme dipeptidyl peptidase type 4 (DDP4) [6].

In vitro and studies with PAH-induced animals indicates that GLP1 promotes vasorelaxation in the pulmonary artery [7,8]. Case reports show an improvement in the history of $\mathrm{PAH}$ in obese patients who underwent bariatric surgery, which in addition to reducing weight, also increases serum GLP-1 levels [9].

In order to prove the beneficial effect of GLP-1 in the treatment of $\mathrm{PAH}$, one way to increase the levels of this hormone without inducing weight loss would be to use a class of oral antidiabetics, called DDP4 inhibitors. Next, we will report the case of a diabetic patient, obesity and with PAH after starting vildagliptin use.

\section{Case report}

A 74-year-old female patient was referred to an endocrinologist in February/14, reporting a previous diagnosis of T2D, dyslipidemia, hypertension and PAH. Physical examination had $67 \mathrm{~kg}$, height $1.49 \mathrm{~m}$, body mass index (BMI) $30.2 \mathrm{~kg} / \mathrm{m}^{2}$ (obesity grade I), blood pressure $135 \times 90 \mathrm{mmHg}$ and dyspnea complaint. He used glyburide $5 \mathrm{mg} /$ day, atorvastatin $20 \mathrm{mg} /$ day and losartan $50 \mathrm{mg} \mathrm{2x} /$ day. Laboratory tests indicated good metabolic control with glycemia of fasting $107 \mathrm{mg} /$ $\mathrm{dL}$, glycated hemoglobin (HbA1c) 6.2\%, total cholesterol 122, HDL-c 58, triglycerides 100 and LDL-c 44. Even in the use of losartan, the patient had symptoms of pulmonary hypertension and transthoracic echocardiogram indicated systolic pressure of the right ventricule (SPRV) of $45 \mathrm{mmHg}$.

Despite the adequate value of $\mathrm{HbAlc}$, the use of glyburide caused several episodes of hypoglycemia in the patient. With a view to better glycemic control, without the risk of hypoglycemia, and the possibility of increasing serum levels of native GLP1, we switched the sulfonylurea for a DDP4 inhibitor, vildagliptin $50 \mathrm{mg} 2 \mathrm{x}$ /day to raise levels of native GLP-1.

After six months with the new oral antidiabetic, the patient returns with new exams and without any pulmonary symptoms reporting a significant improvement in dyspnea. At physical examination, he maintained the same weight and BMI, laboratory tests with glycemia of fasting $111 \mathrm{mg} / \mathrm{dL}$ and $\mathrm{HbAlc} 6.0 \%$, without new episodes of hypoglycemia. A new echocardiogram indicated an improvement of the PAH picture with a SPRV of $38 \mathrm{~mm} \mathrm{Hg}$.

Correspondence to: Flavio Fontes Pirozzi, Endocrinologist,UNILAGO Medical School, Sao Jose do Rio Preto, Brazil, E-mail: fpirozzi@hotmail.com

Key words: metabolic syndrome, type 2 diabetes, pulmonary arterial hypertension, glucagon-like peptide 1

Received: May 05, 2017; Accepted: May 25, 2017; Published: May 29, 2017 
During 3 years the patient remained asymptomatic and with good glycemic control. In the last consultation (January/17), still using vidagliptin $50 \mathrm{mg}$ 2x/day, presented a weight of $68 \mathrm{~kg}$, BMI $30.6 \mathrm{Kg} /$ $\mathrm{m}^{2}$ and the laboratory tests a fasting glycemia of $112 \mathrm{mg} / \mathrm{dL}$ and $\mathrm{HbAlc}$ $6.5 \%$. The echocardiogram indicated a SPRV of $31 \mathrm{mmHg}$.

\section{Discussion}

Previous studies point to an important relationship between diabetes and $\mathrm{PAH}$. The HbA1c dosage has a prognostic value at the time of the diagnosis of PAH. Patients with HbAlc> 5.7\% had lower survival rates [10]. In patients with glucose intolerance and $\mathrm{PAH}$, patients with $\mathrm{HbA} 1 \mathrm{c}<6.0 \%$ obtained better respiratory evaluation on a 6-minute walk test [11].

The change in PPARgamma can lead to vascular damage in the pulmonary circulation and proliferation in the pulmonary circulation [3]. The use of rosiglitazone, a PPARgamma agonist, promoted pulmonary artery vasorelaxation in an in vitro study [12]. Another curious fact is the improvement of obese patients with $\mathrm{PAH}$ after undergoing bariatric surgery, which, in addition to inducing significant weight loss, also promotes an increase in incretin secretion, including GLP-1 [9].

Research shows the presence of GLP-1 receptors in the lungs [13]. In addition to several important metabolites, GLP-1 presents some pleiotropic effects that are still little known. Studies show that GLP1 in the lungs increases the production of surfactant [14], acts as an anti-inflammatory in acute respiratory failure [15], and also promotes vasorelaxation in the pulmonary artery $[7,8]$.

Previously, we had already demonstrated this effect when using a DPP4 inhibitor (vidagliptin $50 \mathrm{mg} 2 \mathrm{x} /$ day) in two obese patients with T2D and PAH. In both cases, after six months of the introduction of this type of oral antidiabetic without weight reduction, there was a significant reduction in SPRV [16].

In this three-year follow-up of one of these patients shows new effects of this drug. In addition to being a safe and effective medication for glycemic control of T2D, vildagliptin was also important in improving PAH, with reduction of SPRV in the first six months of treatment, and throughout this period, it was able to maintain normal levels of SPRV.

\section{Conclusion}

There is an important relationship between MS and PAH and different pathophysiological pathways of diabetes are interrelated with the onset of PAH. Despite the possible beneficial effect of weight loss, the increase in GLP-1 seems to have an important connection in the improvement of PAH. The use of DDP4 inhibitors or GLP-1 analogues are two interesting options for patients with $\mathrm{T} 2 \mathrm{D}$ and $\mathrm{PAH}$.

\section{References}

1. McLaughlin VV, Langer A, Tan M et al. (2013) Contemporary trends in diagnosis and management of pulmonary arterial hypertension: an initiative to close the care gap. Chest 143(2):324-332. [crossref]

2. Link J, Glazer C, Torres F, Chin K (2011) International Classification of Diseases coding changes lead to profound declines in reported idiopathic pulmonary arterial hypertension mortality and hospitalizations: implications for database studies. Chest 139: 497-504. [crossref]

3. Pugh ME, Hemnes AR(2010) Metabolic and hormonal derangements in pulmonary hypertension: from mouse to man. Int J ClinPractSuppl64(168):5-13. [crossref]

4. Hong AR, Lim S(2015) Clinical characteriscs of metabolic syndrome in Korea, and its comparsion with other Asian countries. J Diabetes Investig 6(5): 508-515.[crossref]

5. Baffi CW, Wood L, Winnica D, Strollo PJ Jr, Gladwin MT, et al. (2016) Metabolic Syndrome and the Lung. Chest 149: 1525-1534. [crossref]

6. DeFronzo RA(2009) From the triumvirate to the ominous octet: a new paradigm for the treatment of type 2 diabetes mellitus. Diabetes 58:773-795. [crossref]

7. Richter G, Feddersen O, Wagner U, Barth P, Göke R, et al. (1993) GLP-1 stimulates secretion of macromolecules from airways and relaxes pulmonary artery. $\mathrm{Am} \mathrm{J}$ Physiol265: L374-381. [crossref]

8. Golpon HA, Puechner A, Welte T et al. (2001)Vasorelaxant effect of glucagon-like peptide-(7-36) amide and amylin on the pulmonary circulation of the rat. RegulPept; 102:81-86. [crossref]

9. Pugh ME, Newman JH, Willians DB et al.(2013) Hemodynamic improvement of pulmonary arterial hypertension after bariatric surgery: potential role for metabolic regulation. Diabetes Care 36:e32-e33. [crossref]

10. Belly MJ, Tiede H, Morty RE et al. (2012) HbA1c in pulmonary arterial hypertension a marker of prognostic relevance? J Heart Lung Transplant 31:1109-1114. [crossref]

11. Pugh ME, Robbins IM, Rice TW et al.(2011) Unrecognized glucose intolerance is common in pulmonary arterial hypertension. J Heart Lung Transplant 30(8):904-911. [crossref]

12. Kozlowska H, Baranowska-Kuczko M, Shlicker E et al.(2013) Relaxation of human pulmonary arteries by PPARy agonists. Naunyn-Schmiedeberg's Arch Pharmacol 386:445-453. [crossref]

13. Wei Y, Mojsov S(1995) Tissue-specific expression of the human receptor for glucagonlike peptide-I: brain, heart and pancreatic forms have the same deduced amino acid sequences. FEBS Lett 358:219-224. [crossref]

14. Romaní-Pérez M, Outeiriño-Iglesias V, Gil-Lozano M et al.(2013) Pulmonary GLP1 receptor increases at birth and exogenous GLP-1 receptor agonists augmented surfactant-protein levels in litters from normal and nitrofen-treated pregnant rats. Endocrinology 154:1144-1155. [crossref]

15. Lim SB, Rubinstein I, Sadikot RT et al. (2011) A novel peptide nanomedicine agaisnt acute lung injury: GLP-1 in phospholipid micelles. Pharm Res28:662-672. [crossref]

16. Pirozzi FF, Fernandes-Dias MA, Zotarelli-Filho IJ et al.(2015) Pulmonary artery relaxation was best with increasig GLP1 than the metabolic improvement in patients with type 2 diabetes. Diabetes MetabS13.

Copyright: (C2017 Pirozzi FF. This is an open-access article distributed under the terms of the Creative Commons Attribution License, which permits unrestricted use, distribution, and reproduction in any medium, provided the original author and source are credited. 